\title{
Evaluation of the Deltoid Complex in Supination External Rotation Ankle Fractures
}

\author{
by Travis Motley DPM, MS, FACFAS ${ }^{1}$, J. Randolph Clements, DPM, FACFAS ${ }^{2} \square$, \\ Kelly Moxley, DPM $^{3}$, Brian Carpenter, DPM, FACFAS ${ }^{4} \square$, Alan Garrett, DPM, FACFAS ${ }^{5}$
}

The Foot and Ankle Online Journal 3 (4): 1

We present the results of a prospective study of supination external rotation ankle injuries with an isolated fibula fracture on plain radiographs. The purpose of this study was to see if a correlation exists between the preoperative evaluation and the intraoperative arthroscopic evaluation of the deltoid ligament complex in these injuries. Gravity stress radiographs of the ankle were evaluated to assess deltoid ligament competence. If the medial clear space was $\geq 4$ millimeters, injury to the deltoid ligament complex was assumed. We correlated stress radiograph measurements of the medial clear space with arthroscopic evaluation of the deltoid ligament at the time of open reduction internal fixation in 19 patients. Arthroscopic findings demonstrated that of the 19 patients that underwent open reduction internal fixation, 2 (10\%) had intact deltoid ligaments, 2 (10\%) had partial ruptures, and 15 (79\%) had complete rupture of the deltoid ligament. After placement of fixation, the medial clear space on stress gravity films was measured again to confirm reduction.

Key words: Isolated fibula fracture, deltoid ligament, arthroscopy.

Accepted: March, 2010

Published: April, 2010

This is an Open Access article distributed under the terms of the Creative Commons Attribution License. It permits unrestricted use, distribution, and reproduction in any medium, provided the original work is properly cited. @The Foot and Ankle Online Journal (www.faoj.org)

\section{$\mathrm{T}$} he supination-external rotation (SER) injury described by Lauge-Hansen ${ }^{1}$ is the most common type of ankle fracture.,

Address correspondence to: Travis Motley, DPM, MS, FACFAS . John Peter Smith Hospital, 1500 South Main Street, Fort Worth, TX 76104. tmotley@jpshealth.org

\footnotetext{
${ }^{1}$ Assistant Professor, University of North Texas Health Science Center, Department of Orthopaedics, John Peter Smith Hospital, 1500 South Main Street, Fort Worth, TX 76104.

${ }^{2}$ Carilion Clinic, Department of Orthopaedics, Three Riverside Place, Roanoke, VA 24014.

${ }^{3}$ Juneau Foot \& Ankle Center, 8800 Glacier Hwy \#218, Juneau, AK 99801

${ }^{4}$ Associate Professor, University of North Texas Health Science Center,

Department of Orthopaedics, John Peter Smith Hospital, 1500 South Main

Street, Fort Worth, TX 76104.

${ }_{5}^{5}$ Assistant Professor, University of North Texas Health Science Center, Department of Orthopaedics, John Peter Smith Hospital, 1500 South Main Street, Fort Worth, TX 76104.
}

SER injuries begin anteriorly and progress in a clockwise fashion so that stage I injury includes the anterior inferior tibiofibular ligament. As rotation of the talus continues, stage II will involve either rupture of the lateral ankle ligaments or a fracture of the fibula at the level of the ankle joint. With continued progression, stage III involves either an injury to the posterior talofibular ligament or an avulsion injury of the posterior malleolus. Stage IV includes injury to either the deltoid ligament complex or a fracture of the medial malleolus. The surgeon can easily determine that the fracture is unstable when the medial malleolus is broken. However, determining fracture instability based on deltoid ligament competency is more challenging. 


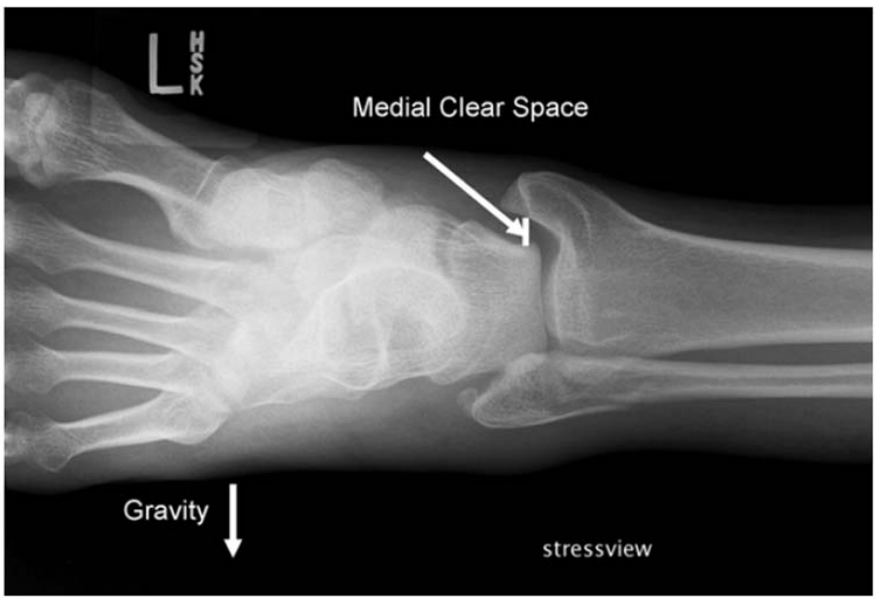

Figure 1 Technique for measurement of the medial clear space (MCS) on stress gravity view.

Some surgeons still rely on medial tenderness, swelling, or ecchymosis as indicators of deltoid ligament incompetency. The oversight here is that the deltoid ligament is a composite of two ligaments: deep and superficial. The superficial deltoid includes the anterior tibiotalar ligament and the tibionavicular ligament. The posterior tibiotalar and tibiocalcaneal ligament make up the deep deltoid component.

Pankovich and Shivaram ${ }^{4,5}$ demonstrated differences and roles of the superficial and deep components. The superficial deltoid ligament can be completely or partially torn and still produce "medial tenderness, swelling and ecchymosis." If soft tissue indicators alone are used, many stable (non-displaced SER II) fractures will be treated operatively.

Stage II SER injuries with an isolated non-displaced fibula fracture are generally treated non-operatively, but fracture patterns that progress to medial injury (SER IV) are generally treated with open reduction internal fixation (ORIF).

Clinically, distinguishing between an isolated fibula fracture (SER II) and an injury that includes a medial ligamentous injury (SER IV) can be difficult.
Previous authors have shown that medial tenderness, bruising, or ecchymosis are unreliable predictors of medial ligamentous injury. ${ }^{6,7,8}$

Some authors report stress radiographs have a better prognostic value when evaluating for ligamentous SER IV (bimalleolar equivalent) injuries., ${ }^{9,10}$ Evaluation of the medial clear space (MCS) in these bimalleolar equivalent injuries on stress radiographs has shown that American Orthopaedic Foot and Ankle Society Ankle and Hindfoot Functional Survey scores decline with an increase in $\mathrm{MCS}^{11}$ when treated conservatively.

The purpose of this study was to see if a correlation exists between the preoperative evaluation and the intraoperative arthroscopic evaluation of the deltoid ligament complex in SER IV (bimalleolar equivalent) ankle fractures.

\section{Materials and Methods}

Patients included in this study were consulted to the podiatry service at our institution with an isolated closed distal non-displaced/minimally displaced fibula fracture with and a widened medial clear space (MCS) $\geq 4$-mm on gravity stress views. After informed consent was obtained, patients underwent ORIF with ankle arthroscopy. At the time of arthroscopy, the deltoid ligament was noted as intact, partial tear, or ruptured. Talar dome lesions evident during arthroscopy were also documented.

Radiographic measurements for each patient preoperatively included MCS on standard mortise and stress gravity views, preoperative superior clear space (SCS), preoperative contralateral stress gravity, and postoperative stress gravity views. The MCS was measured as the distance between the medial border of the talus and the lateral border of the medial malleolus on a line parallel and 5-mm below the talar dome. (Fig. 1) The SCS was the distance between the distal tibia and the highest point of the talar dome. 


\begin{tabular}{|c|c|c|c|c|}
\hline $\begin{array}{l}\text { Deltoid } \\
\text { Ligament }\end{array}$ & X-ray type & $\begin{array}{l}\text { Mean } \\
(\mathrm{mm})\end{array}$ & $\begin{array}{l}\text { Difference in mean MCS standard vs. } \\
\text { stress gravity views (mm) }\end{array}$ & Mean post-operative MCS reduction (mm) \\
\hline \multirow{4}{*}{$\begin{array}{l}\text { Intact } \\
\text { (2 patients) }\end{array}$} & MCS & 3.44 & & \\
\hline & MCS SG & 5.37 & 1.93 & \\
\hline & MCS CL & 2.84 & & \\
\hline & MCS PO & 2.83 & & 2.54 \\
\hline \multirow{4}{*}{$\begin{array}{l}\text { Partial tear } \\
\text { (2 patients) }\end{array}$} & MCS & 3.53 & & \\
\hline & MCS SG & 5.24 & 1.71 & \\
\hline & MCS CL & 2.97 & & \\
\hline & MCS PO & 2.43 & & 2.81 \\
\hline \multirow{4}{*}{$\begin{array}{l}\text { Ruptured } \\
\text { (15 } \\
\text { patients) }\end{array}$} & MCS & 5.44 & & \\
\hline & MCS SG & 9.1 & 3.66 & \\
\hline & MCS CL & 3.14 & & \\
\hline & MCS PO & 3.47 & & 5.63 \\
\hline
\end{tabular}

Table 1 Medial clear space (MCS) measurements in patients with an intact deltoid ligament, partially torn deltoid ligament, and those with ruptured deltoid ligaments as demonstrated on arthroscopic evaluation. MCS = medial clear space on pre-operative mortise view, MCS SG = medial clear space on stress gravity view, MCS CL = medial clear space on contralateral mortise view, MCS PO = medial clear space post-operative views.

\section{Results}

Nineteen patients met the specific inclusion criteria of an isolated distal non-displaced/minimally displaced fibula fracture and a MCS $\geq 4-\mathrm{mm}$. From arthroscopic evaluation, fifteen patients (79\%) were found to have a complete rupture of the deltoid ligament on arthroscopic evaluation, two (10.5\%) were found to have a partial tear, and two (10.5\%) were found to have an intact deltoid ligament. Generally, patients with higher MCS values were found to have complete rupture of the deltoid complex while those with lower MCS values were found to have intact or only partial deltoid tears. The average MCS in the patient group found to have a complete rupture of the deltoid ligament was 5.44$\mathrm{mm}$. (Table 1). Stress gravity views also demonstrated an increase in MCS from standard radiographic ankle views. Arthroscopic evaluation also identified talar dome lesions in $7(37 \%)$ of our patients. Of these, $3(16 \%)$ were medial, $3(16 \%)$ were lateral, and $1(5 \%)$ were centrally located within the talar dome. Due to the limited size of this data set, statistical analysis is not feasible to draw any meaningful conclusions.

\section{Discussion}

The SER mechanism is the most common pattern observed with ankle fractures. ${ }^{2,3}$ Isolated nondisplaced fibula fractures are routinely treated nonoperatively. However, SER IV injuries involving the deltoid ligament complex represent unstable ankles and the consensus amongst foot and ankle surgeons is that SER IV ankle fractures should be treated surgically in order to restore anatomic alignment and stability to the ankle joint. Several publications have shown the advantages of proper treatment of these injuries. ${ }^{12-15}$ The purpose of our study was to see if a correlation exists between the preoperative evaluation and the intraoperative arthroscopic evaluation of the deltoid ligament complex in SER IV (bimalleolar equivalent) ankle fractures.

Open reduction and internal fixation of SER IV injuries is widely considered standard. Some authors have advocated ORIF in those bimalleolar equivalent injuries where the MCS value is $\geq 4-\mathrm{mm}$. 
Clements, et al., ${ }^{11}$ has shown previously that patients with an MCS value of up to $5-\mathrm{mm}$ do well (measured with AOFAS hindfoot and ankle functional satisfaction survey) without operative intervention. These authors suggest that MCS values less than 5$\mathrm{mm}$ may represent those patients with only a partial tear of the deltoid ligament complex and subsequently a more stable ankle than those patients with complete deltoid ligament rupture.

Schuberth, et al., ${ }^{8}$ concluded that a widened medial clear space was not an indicator of deltoid ligament rupture in their correlation between radiographic and arthroscopic evaluation in their patients. We found that 2 of our 19 patients had an intact deltoid ligament with arthroscopic evaluation and a gravity stress radiographic finding of MCS $>5-\mathrm{mm}$. We consider this more of an exception and suggest that any bimalleolar equivalent injury with an MCS $>5$ $\mathrm{mm}$ be carefully evaluated and correlated to the contralateral ankle.

The traditional use of medial tenderness, swelling, and ecchymosis in conjunction with a lateral malleolar fracture is no longer reliable as a means of accurately determining medial side injury. These signs were thought to suggest deltoid ligament rupture; however, recent literature is replete with data that clinical symptoms of medial tenderness, swelling, and ecchymosis are not predictive of deltoid ligament disruption. ${ }^{16,17}$ Because of the uncertainty in these physical findings, clinicians rely more on gravity stress or medial stress radiographs. These radiographs apply force by either gravity or manual rotation to the deltoid ligament complex. An anterior-posterior image is taken. If the medial clear space widens past $4 \mathrm{~mm}$, the presumption is that the deep deltoid ligament has failed and can no longer tether the talus to the medial malleolus. The authors of this study directly visualized the deep deltoid by arthroscopy to determine if there was a direct correlation between widening of the medial clear space and deep deltoid ligament incompetency.
Since, $9 \%$ of the patients in this study had intact deep deltoid ligaments by arthroscopy but showed widened medial clear space measurements radiographically, one must assume the deep deltoid ligament is attenuated during the injury. The question remains if this attenuation of the deep deltoid ligament creates significant tibiotalar instability. Ramsey and Hamilton $^{18}$ suggested that a $1-\mathrm{mm}$ displacement increases the contact forces of the tibiotalar joint by $42 \%$.

Other techniques have been described to evaluate the deltoid ligament complex. Magnetic resonance imaging provides the best non invasive means of evaluating the deltoid ligament complex. However, the cost is prohibitive at this point. Ultrasound provides a less costly, non-invasive way to evaluate the deep deltoid. Chen, et al., ${ }^{19}$ examined with sonography to evaluate the deltoid ligament. Patients who showed complete rupture of the deltoid ligament received operative treatment. During surgical repair of the fibula, a medial exploration was performed to confirm deep deltoid ligament disruption. A recent publication simply used weight-bearing radiographs to distinguish stable and unstable SER fractures. Patients with questionable injuries (SER II versus SER IV) had weight- bearing radiographs. In this experiment, the use of weight bearing radiographs was used to determine the need for operative treatment. If ankle joint congruity was appreciated on weight-bearing films, $90 \%$ of the patients were treated successfully with non-operative treatment. ${ }^{20}$

Current literature suggests that a compromised deltoid ligament complex can be demonstrated in non-displaced fibula fractures by many methods. Probably the most common modality is the gravity stress radiograph because it does not require special equipment and can be rapidly performed using standardized techniques. Medial clear space measurements $\geq 4-\mathrm{mm}$ on gravity stress films have been assumed to correlate to deltoid ligament incompetence. However, based on data obtained in this small study and a previous study published by our group $^{11}$, medial clear space values may need to be reassessed. 
We propose that a medial clear space measurement $\leq$ 5 - $\mathrm{mm}$ in non-displaced fibula fractures may do well with conservative treatment as this likely represents only a partially torn deltoid ligament. A larger study group with arthroscopic evaluation of the deltoid ligament in patients with medical clear space measurements of $5-\mathrm{mm}$ treated conservatively and those treated operatively with outcome measures would be beneficial.

\section{Conclusion}

Deltoid ligament competency can be established with a stress gravity view on presentation. We further evaluated the deltoid ligament complex with arthroscopy at the time of ORIF in these bimalleolar equivalent ankle injuries. We used arthroscopy to confirm widened medial clear space values indeed correlates to a disruption of the deep deltoid ligament. Furthermore, patients who only widened to $5 \mathrm{~mm}$ on stress gravity images are more likely to have a partially torn deltoid ligament. These represent stable ankle fracture and should be considered for non- operative treatment. There is a high correlation between MCS on stress views and incompetent deltoid ligaments. The extent of subtle deltoid ligament injuries is difficult to determine. Advanced imaging modalities may prove to be superior to stress imaging. Our findings support other recent publications that the medial clear space measurement used to determine deep deltoid ligament incompetency could be increased to $5 \mathrm{~mm}$.

\section{Conflicts of Interest}

The authors report no conflict of interest.

\section{References}

1. Lauge-Hansen N. Fractures of the ankle II. Combined experimental-surgical and experimental-roentgenologic investigations. Arch Surg 1950 60: 957-985.

2. Jensen SL, Andresen BK, Menche S, Nielsen PT. Epidemiology of ankle fractures. A prospective populationbased study of 212 cases in Aalborg, Denmark. Acta Orthop Scand 1998 69: 48-50.

3. Yde J. The Lauge Hansen classification of malleolar fractures. Acta Orthop Scand 1980 51: 181-92.
4. Pankovich AM, Shivaram MS. Anatomical basis of variability in injuries of the medial malleolus and the deltoid ligament. I. Anatomical studies. Acta Orthop Scand 1979 50: 217-223.

5. Pankovich AM, Shivaram MS. Anatomical basis of variability in injuries of the medial malleolus and the deltoid ligament. II. Clinical studies. Acta Orthop Scand 1979 50: 225-236.

6. McConnell T, Creevy W, Tornetta PIII. Stress examination of supination external rotation-type fibular fractures. JBJS 2004 86A (10): 2171-2178.

7. Egol KA, Amirtharajah M, Tejwani NC, Capla EL, Koval KJ. Ankle stress test for predicting the need for surgical fixation of isolated fibular fractures. JBJS 86A (11): 2393-2399.

8. Schuberth JM, Collman DR, Rush SM, Ford LA. Deltoid ligament integrity in lateral malleolar fractures: a comparative analysis of arthroscopic and radiographic assessments. J Foot Ankle Surg 2004 43(1): 20-29.

9. Park SS, Kubiak KA, Kummer F, Koval KJ. Stress radiographs after ankle fracture. J Orthop Trauma 2006 20(1): 11-18.

10. Gill B, Risko T, Raducan V, Grimes JS, Schutt Jr, RC. Comparison of manual and gravity stress radiographs for the evaluation of supination-external rotation fibular fractures. JBJS 2007 89A (5): 994-999.

11. Clements JR, Motley TA, Garrett A, Carpenter BB. Nonoperative treatment of bimalleolar equivalent ankle fractures: a retrospective review of 51 patients. J Foot Ankle Surg 2008 47(1): 40-45.

12. Michelson JD. Fractures about the ankle. JBJS $199577 \mathrm{~A}$ (1):142-152.

13. Joy G, Patzakis MJ, Harvey JP Jr. Precise evaluation of the reduction of severe ankle fractures. JBJS 1974 56A (5): 979-993.

14. Mont MA, Sedlin ED, Weiner LS, Miller AR. Postoperative radiographs as predictors of clinical outcome in unstable ankle fractures. J Orthop Trauma 1992 6:352 -357.

15. Burns WC 2nd, Prakash K, Adelaar R, Beaudoin A, Krause W. Tibiotalar joint dynamics: indications for the syndesmotic screw-a cadaver study. Foot Ankle 1993 14:153-158.

16. Egol KA, Amirtharajah M, Tejwani NC, Capla EL, Koval $\mathrm{KJ}$. Ankle stress test for predicting the need for surgical fixation of isolated fibular fractures. JBJS 2004 86A (11): 2393-2398. (Erratum in: JBJS 2005 87A: 857. Erratum in: JBJS 2005 87A:161).

17. McConnell T, Creevy W, Tornetta P 3rd. Stress examination of supination external rotation-type fibular fractures. JBJS 2004 86A (1): 2171-2178.

18. Ramsey PL, Hamilton W. Changes in tibiotalar area of contact caused by lateral talar shift. JBJS 1989 71A (3): 15481555.

19. Chen PY, Wang TG, Wang CL. Ultrasonographic examination of the deltoid ligament in bimalleolar equivalent fractures. Foot Ankle Int 2008 29(9): 883-886.

20. Weber M, Burmeister H, Flueckiger G, Krause FG. The use of weightbearing radiographs to assess the stability of supination-external rotation fractures of the ankle. Arch Orthop Trauma Surg Epub 2010 Jan 16. 